\title{
Laser in situ monitoring of combustion processes
}

\author{
A. Arnold, H. Becker, R. Hemberger, W. Hentschel, W. Ketterle, M. Kollner, W. Meienburg, \\ P. Monkhouse, H. Neckel, M. Schafer, K. P. Schindler, V. Sick, R. Suntz, and J. Wolfrum
}

\begin{abstract}
Several examples of laser in situ monitoring of combustion processes are presented. Using a frequency modulated ${ }^{13} \mathrm{CO}_{2}$ waveguide laser, in situ concentrations of $\mathrm{NH}_{3}$ down to $1 \mathrm{ppm}$ were measured at temperatures up to $600^{\circ} \mathrm{C}$ in waste incinerators and power or chemical plants. Following ignition of $\mathrm{CH}_{3} \mathrm{OH}-\mathrm{O}_{2}$ mixtures by a $\mathrm{TEA} \mathrm{CO} \mathrm{CO}_{2}$ laser, gas temperature profiles were measured using rapid scanning tunable diode laser spectroscopy of $\mathrm{CO}$ molecules. In laminar $\mathrm{CH}_{4}$-air counterflow diffusion flames at atmospheric pressure absolute concentrations, temperatures, and collisional lifetimes of $\mathrm{OH}$ radicals were determined by 2-D and picosecond LIF and absorption spectroscopy. Two-dimensional LIF and Mie scattering were used to observe fuel injection and combustion in a diesel engine. Key words: Combustion diagnostics, laser-induced fluorescence, counterflow diffusion burner, diesel engine, temperature measurement, laser-induced ignition, measurement of ammonia concentration.
\end{abstract}

\section{Introduction}

Since the first use of fire by mankind, combustion technology has been a major driving force behind a modern industrial society. However, the drastic increase in the consumption of primary fossil energy in the last hundred years has created a situation in which local and global environmental effects can no longer be neglected. This fact, together with the economic importance of fossil energy, provides the main motivation for the great efforts to improve the efficiency of combustion processes and simultaneously reduce the emission of pollutants. In recent years, several laser-based spectroscopic methods with high spectral, temporal, and spatial resolution have been successfully applied for nonintrusive measurements of temperatures, species concentrations, and gas velocities in combustion. The major challenge in the application of such new laser-diagnostic methods in combustion is to provide quantitative data for a comparison to mathematical

H. Neckel is with Mutek GmbH, Fost 1110, D-8036 Herrsching, Federal Republic of Germany; W. Hentschel and K. P. Schindler are with Volkwagen Research, D-3180 Wolfsburg, Federal Republic of Germany; and the other authors are with Heidelberg University, Physical Chemistry Institute, $253 \mathrm{Im}$ Neuenheimer Feld, D-6900 Heidelberg, Federal Republic of Germany.

Received 19 March 1990.

0003-6935/90/334860-13\$02.00/0.

(C) 1990 Optical Society of America. simulation models for the complex interaction of elementary chemical reactions and multidimensional transport processes. In this paper, a number of experimental results in systems with an increasing order of complexity in the interaction of chemical reactions and transport processes are described.

\section{In Situ Measurement of Ammonia Concentration in Industrial Combustion Systems}

This work was initiated to improve the nitrogen oxide reduction process in power plants. Nitric oxide can be converted to nitrogen and water either catalytically or by the thermal $\mathrm{De}-\mathrm{NO}_{x}$ process $^{1}$ by direct reaction with the $\mathrm{NH}_{2}$ radical. ${ }^{2}$ In both cases the consumption of ammonia has to be as complete as possible, since the reaction of any residual ammonia with sulfur oxides also present in the flue gas will lead to the formation of solid ammonium hydrogen sulfate, which can cause severe damage in the plants. Thus a fast responding ammonia detection system is needed especially to control the mixing of the chemicals injected in the flue gases. In addition, the detection of ammonia is of increasing interest as a pollutant emerging from various industrial processes. ${ }^{3-8}$ The instruments commonly used up to now determined the ammonia concentration through a gas suction probe, which gives rise to major problems. First, conventional chemical analysis requires sampling times of 30-90 min. Second, a delay of up to half an hour was caused by well absorption processes in the probing line. In many applications, differences of up to $20 \mathrm{ppm}$ have been observed between the measured values of probes sucked at different points in the flue gas. This is 


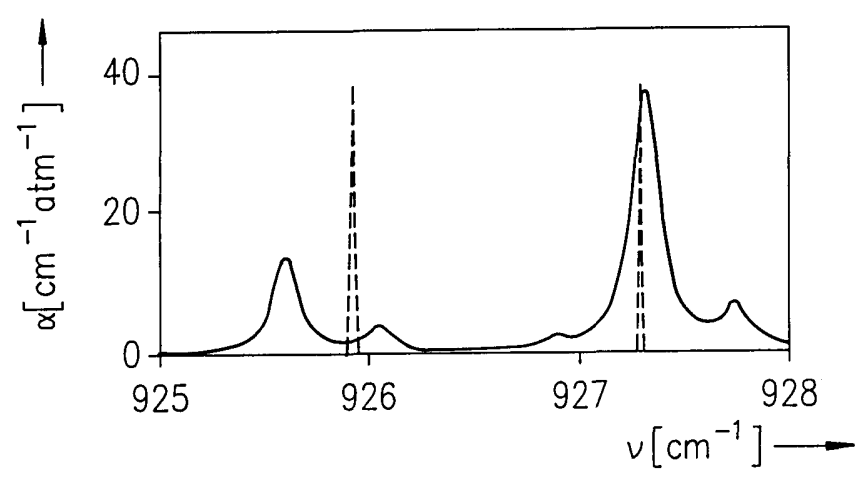

Fig. 1. Infrared diode laser absorption spectra of $\mathrm{NH}_{3}$ at STP (—) and ${ }^{13} \mathrm{CO}_{2}$ laser emission lines (- - -).

considerably more than the usual allowed maximum residual ammonia concentration of $5 \mathrm{ppm}$. To avoid these disadvantages, an in situ method is needed that measures ammonia concentrations in hot flue gases with a short time constant and a detection limit in the 1-ppm range. This was achieved by a differential laser absorption technique. The laser in situ ammonia monitoring system described here is based on a commercially available ${ }^{13} \mathrm{CO}_{2}$ laser. This system is robust enough to work even in rough industrial environments. To enable the technique to be applied at higher temperatures, the line strength and width of the relevant ammonia absorption lines have been measured with a high resolution tunable IR diode laser system up to 660 K. ${ }^{9}$

The determination of species concentration by differential absorption techniques is based on the Lambert-Beer law:

$I(\nu)=I_{0}(\nu) \exp [-a(\nu) c l]$,

which relates the incident and transmitted spectral intensities $I_{0}(\nu), I(\nu)$ to the absorption coefficient $a(\nu)$ at frequency $\nu$, the concentration $c$, and the measurement path length $l$. Letting $\nu_{1}, \nu_{2}$ denote the laser emission lines nearly coinciding with the $\mathrm{NH}_{3}$ absorption maximum and minimum, respectively, the $a b-$ sorption coefficients can be written

$$
\begin{aligned}
& a\left(\nu_{1}\right)=a_{1}+a_{\mathrm{NH}_{3}}, \\
& a\left(\nu_{2}\right)=a_{1} .
\end{aligned}
$$

Here $a_{1}$ includes all background attenuation of the probing beam due to reflection losses such as scattering at smoke particles and can be taken to be constant if $\nu_{1}$ and $\nu_{2}$ are close together. $a_{\mathrm{NH}_{3}}$ is the difference between the $\mathrm{NH}_{3}$ absorption coefficient at $\nu_{1}$ and $\nu_{2}$, while the $\mathrm{NH}_{3}$ absorption at $\nu_{2}$ is small compared to the value at $\nu_{1}$ (Fig. 1). The ratio of the transmitted intensities,

$$
I\left(\nu_{1}\right) / I\left(\nu_{2}\right)=I_{0}\left(\nu_{1}\right) / I_{0}\left(\nu_{2}\right) \exp \left(-a_{\mathrm{NH}_{3}} c l\right),
$$

depends on the ratio of the intial intensities, which can be determined in a reference beam and detector. If $I^{R}\left(\nu_{1}\right), I^{R}\left(\nu_{2}\right)$ denote the intensities at the reference detector, the $\mathrm{NH}_{3}$ concentration results in

$$
c=-1 /\left(a_{\mathrm{NH}_{3}} l\right) \ln \left[I\left(\nu_{1}\right) / I\left(\nu_{2}\right) I^{R}\left(\nu_{2}\right) / I^{R}\left(\nu_{1}\right)\right] .
$$

Hence the most important variable to be known is $a_{\mathrm{NH}_{3}}$, which is temperature and pressure dependent. For a collision broadened line, the absorption coefficient at frequency $\nu_{1}$ can be described by

$$
a_{\mathrm{NH}_{3}}=S(T) g(T, P)\left\{p\left[\left(\nu_{1}-\nu_{0}\right)^{2}+g(T, P)^{2}\right]\right\}^{-1},
$$

where $S$ is the spectral line strength, $g$ is the halfwidth, and $\nu_{0}$ is the frequency of the $\mathrm{NH}_{3}$ absorption line center. In the present field of application only slight deviations from atmospheric pressure are expected, and thus $g(T, P)$ can be approximated fairly well by ${ }^{9}$

$$
g(T, P)=P / P_{0}[\alpha-\beta T],
$$

where $\alpha=0.149 \mathrm{~cm}^{-1}, \beta=1.43 \times 10^{-4} \mathrm{~cm}^{-1} / \mathrm{K}, P_{0}=1$ atm. The temperature dependence of $S(T)$ is given theoretically by

$$
S\left(T^{\prime}\right)=S_{0} \nu \nu_{0}^{-1} \exp (-h c E / k T)[1-\exp (-h c \nu / k T)] g H Q^{-1},
$$

where $S_{0}$ is the total band strength, $\nu$ is the wavenumber of the transition, $\nu_{0}$ is the wavenumber of the band center, $E$ is the energy $\left(\mathrm{cm}^{-1}\right)$ of the lower level involved in the transition, $g$ is the statistical weight, $H$ is the Honl-London factor, and $Q$ is the total partition function. ${ }^{10}$ With $S(T)$ and $g(T, P)$ known, Eqs. (5) and (6) enable an absolute determination of the $\mathrm{NH}_{3}$ concentration by differential absorption to be made. Due to the isotope shift, the overlap of the ${ }^{13} \mathrm{C}^{16} \mathrm{O}_{2}$ tunable waveguide laser emission lines and the absorption lines of ${ }^{12} \mathrm{CO}_{2}$, of which large amounts are present in the stack gas, is significantly reduced. Calculations based on the AFGL data compilation ${ }^{11}$ show that there are no significant spectral interferences with any other component of the flue gas.

The two laser lines are generated alternately with the same laser. Switching between the lines is achieved by modulating the resonator length using a piezoelement. The high frequency of the switching (2 $\mathrm{kHz}$ ) ensures that the referencing is fast enough to autocalibrate the system continuously (Fig. 2).

A computer simulation of the spectrum between 925 and $928 \mathrm{~cm}^{-1}$ of a mixture of 0.015 -atm $\mathrm{cm} \mathrm{H}_{2} \mathrm{O}, 0.015$ atm cm CO, 0.002 -atm $\mathrm{cm} \mathrm{N} \mathrm{N}_{2} \mathrm{O}$, and $1 \times 10^{-6}$-atm $\mathrm{cm}$ $\mathrm{NH}_{3}$ diluted in pure nitrogen at STP, based on the data of the AFGL compilation, ${ }^{11}$ confirms $^{9}$ that the selected lines lie in a suitable type of atmospheric window. The $R(18){ }^{13} \mathrm{CO}_{2}$ laser line coincides with the strong $a Q(6,6) \mathrm{NH}_{3}$ absorption line. ${ }^{12}$ The line separation amounts to only $0.018 \mathrm{~cm}^{-1}$, and the $\mathrm{NH}_{3}$ absorption of the $R(16)$ laser line is sufficiently small (Fig. 1 ).

The experimental setup is shown schematically in Fig. 2. The laser, spectrum analyzer $S A$, detectors $D$, optical elements such as mirrors $M$, and beam splitters $B S$ are mounted on a compact solid platform. The laser beam is split into three parts. One is directed into the spectrum analyzer to check whether the laser is stabilized on the correct lines. The second beam serves as a reference yielding $I_{0}\left(\nu_{1}\right) / I_{0}\left(\nu_{2}\right)$. The third beam is used as a sensor to cross the flue gas channel. The high average laser power of $\sim 1 \mathrm{~W}$ (compared, e.g., 


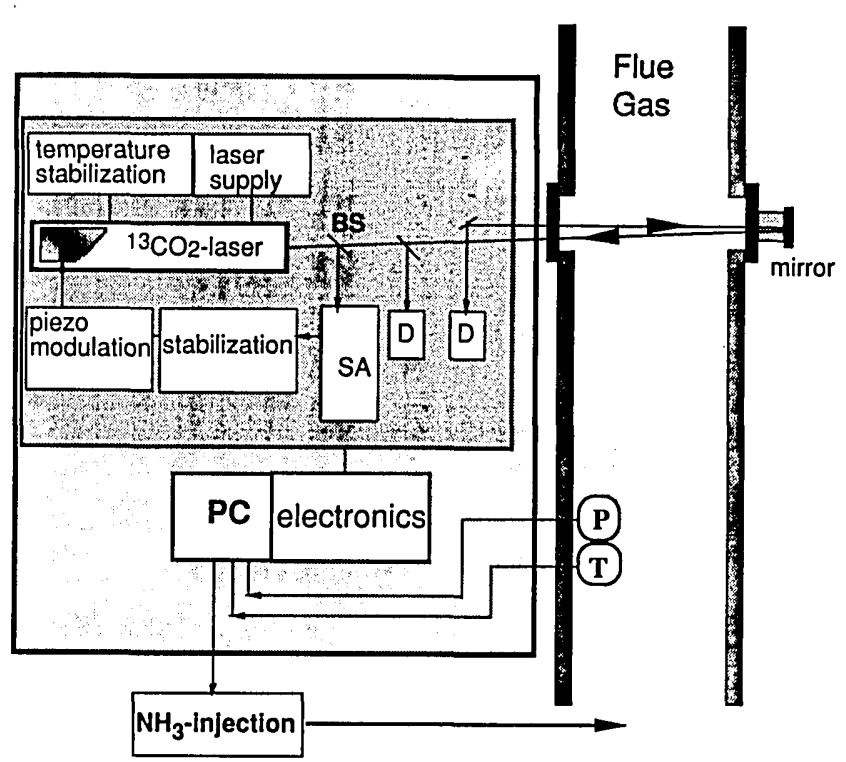

Fig. 2. Schematic of the ${ }^{13} \mathrm{CO}_{2}$ laser-based $\mathrm{NH}_{3}$ detection system: $D$, detector; $S A$, spectrum analyzer; $B S$, beam splitter.

with $1 \mathrm{~mW}$ of a typical diode laser) allows a long measuring path length, even in dusty gases. The beam is reflected by a mirror mounted onto the opposite wall and returns almost on itself. Special care had to be taken to avoid etalon effects in the optical beam path, which would falsify the intensity ratios. The preamplified detector signals are processes in electronic equipment that is synchronized to the piezomodulation frequency. This synchronization ensures that the referencing is done almost instantaneously. The final calculation of the absolute concentration is carried out by a desktop personal computer using Eq. (5). The PC enters the actual data of temperature and pressure in appropriate time intervals and calculates $a_{\mathrm{NH}_{3}}$ as a calibration factor using Eq. (6).

The whole system is arranged in three separate units. The laser platform is installed close to the measurement location, and all supply and electronic equipment are located in a rack nearby. Both these units are protected against dust and water. The PC and data documentation represent the third unit, which may be set up in a remote control station.

To check the linearity of the system, the signal was measured for different amounts of $\mathrm{NH}_{3}$ at a constant total pressure of 980 mbar. The optical density was varied between 0 and $850 \mathrm{ppm} \times \mathrm{m}$. The signal was found to be linear over the whole range. The validity of $\mathrm{NH}_{3}$ as a calibration factor was confirmed by investigating the temperature and pressure dependence of $I\left(\nu_{1}\right) / I\left(\nu_{2}\right) \times I^{R}\left(\nu_{2}\right) / I^{R}\left(\nu_{1}\right)$. Excellent agreement with the results of the diode laser measurements was found. At pressures $P>500$ mbar, the pressure dependence of the signal is almost linear and can be approximated by $T=0.147+4 \times 10^{-4}$ - bar $^{-1} P$, where $T$ is the transmittance. This shows that slight pressure variations in the flue gases do not affect the signal.

After these laboratory tests, several measurements

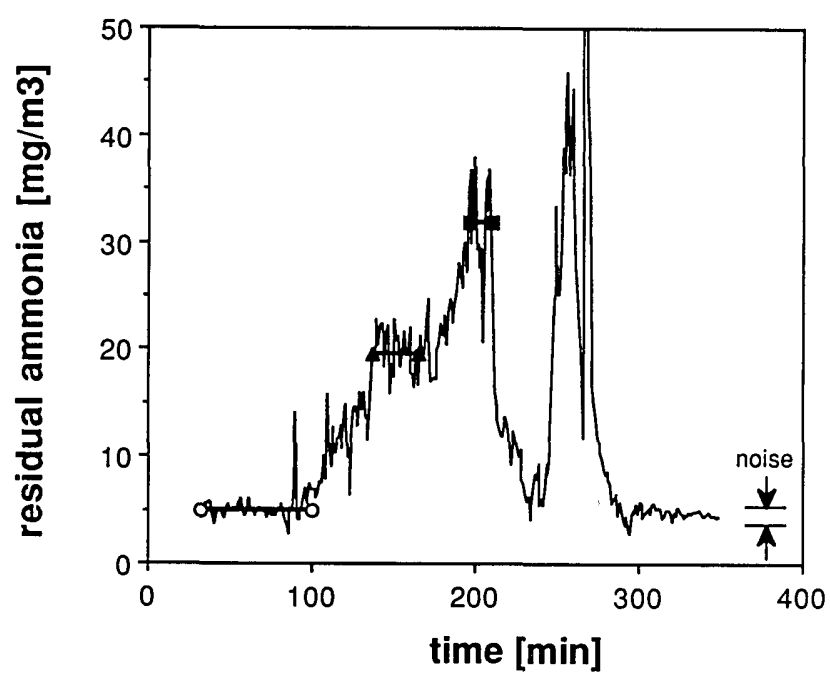

Fig. 3. Residual ammonia in a power plant (300 MW) during experiments with secondary NO reduction $(\bullet$ conventional chemical analysis).

in power plants and in the chemical industry were carried out. The system was found to work reliably, even in a rough environment characterized by strong vibrations and a dusty atmosphere. With path lengths of the order of $10 \mathrm{~m}$, a detection limit of $\sim 1$ ppm was reached.

The response time and dynamic range are shown in Fig. 3 where the injection of $\mathrm{NH}_{3}$ was interrupted for $20 \mathrm{~min}$. The slow decrease of residual $\mathrm{NH}_{3}$ and the measurement times for conventional chemical analysis are shown.

A further use was found in the chemical industry where residual ammonia concentration levels up to 100 $\mathrm{mg} / \mathrm{m}^{3}$ can be observed. Figure 4 shows the signal of the laser system and that of a nondispersive IR analysis (NDIR) using an aspirated gas probe. It is obvious that the time delay of the NDIR instrument is up to half an hour if the ammonia concentration is decreasing. In the case of increasing $\mathrm{NH}_{3}$ concentrations, the time delay is up to $15 \mathrm{~min}$.

An interesting application was also found in waste incinerators. Due to the variations in the combustion process as a result of changing waste composition, the NO emission is irregular. Thus a very fast responding ammonia detection system is needed to control the noncatalytic reduction of $\mathrm{NO}$. The residual $\mathrm{NH}_{3}$ measured by the laser system after reduction of NO with urea is shown in Fig. 5. The strong variations in the $\mathrm{NO}$ emission and the behavior of the residual $\mathrm{NH}_{3}$ are clearly shown.

\section{Time Resolved Temperature Measurements in $\mathrm{CO}_{2}$ Laser-Induced Ignition Processes in $\mathrm{CH}_{3} \mathrm{OH}-\mathrm{O}_{2}$ Mixtures Using Tunable Diode Lasers}

To develop quantitative mathematical models for the complete simulation of ignition processes including detailed chemistry, one is interested in simple experimental situations. In previous investigations, this 


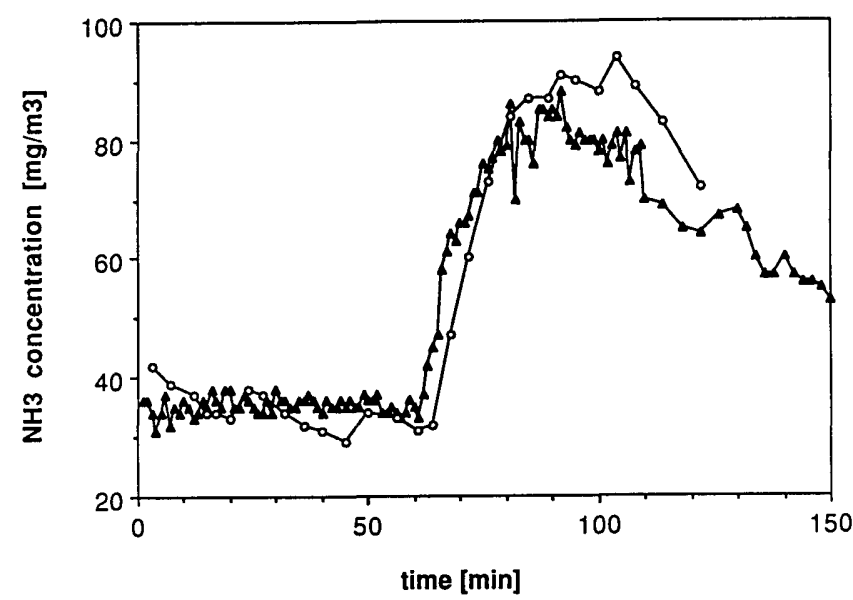

Fig. 4. Temporal progress of $\mathrm{NH}_{3}$ concentration in a chemical plant measured by the laser system $(\Delta)$ and NDIR instrument (O).

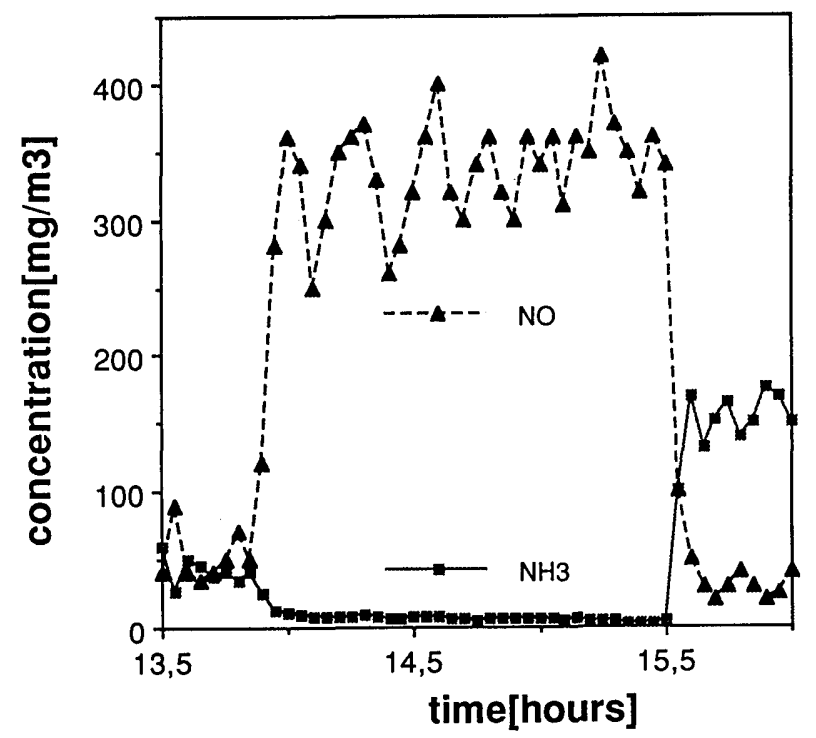

Fig. 5. Temporal progress of $\mathrm{NH}_{3}$ and $\mathrm{NO}$ in a waste incinerator over $3 \mathrm{~h}$ during the reduction with urea.

could be realized by igniting $\mathrm{O}_{3}-\mathrm{O}_{2}$ mixtures in a cylindrical cell by absorption of $\mathrm{CO}_{2}$ laser pulses. ${ }^{13}$ Using time and spatially resolved UV absorption for the detection of ozone, flame front visualizations ${ }^{14}$ and temperature measurements ${ }^{15}$ could be made in these experiments. The experimental results were successfully simulated mathematically in $2-\mathrm{D}$ geometries. ${ }^{16}$ However, the investigations were restricted to the simple $\mathrm{O}_{3}-\mathrm{O}_{2}$ system. More realistic fuels require more time-consuming calculations and further development of diagnostic techniques. An interesting technique for time and spatially resolved temperature measurements is the use of tunable IR diode lasers (TDLs). For measuring temperatures in stationary systems, such as burners, TDL spectroscopy has been applied by scanning over two absorption lines of $\mathrm{CO} \cdot{ }^{17-19}$ In-

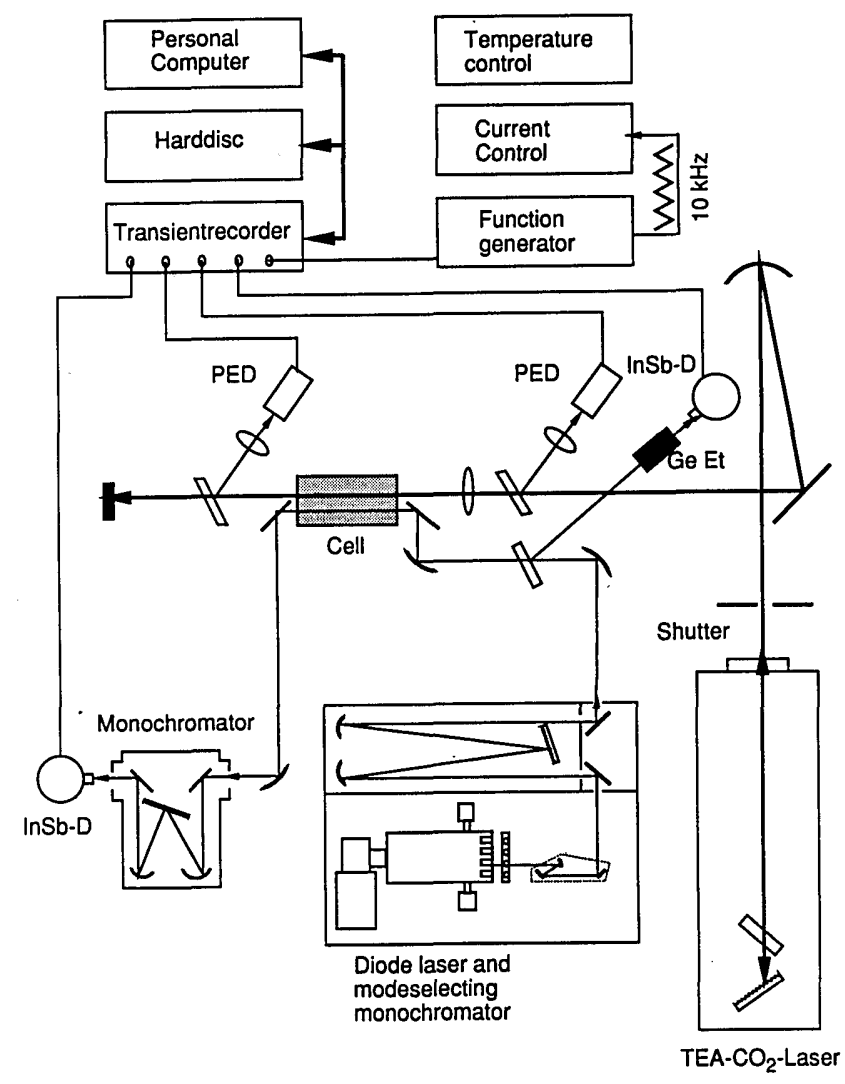

Fig. 6. Experimental setup for the investigation of $\mathrm{CO}_{2}$ laser-induced ignition processes by tunable IR diode laser spectroscopy.

frared absorption spectra of transient intermediates produced by laser-induced dissociation have been made using boxcar techniques. ${ }^{20,21}$ The sweep integration technique ${ }^{22}$ has been shown to yield excellent sensitivity, even with high repetition rates. We have combined these two techniques to examine the temporal and spatial development of temperatures in the $\mathrm{CO}_{2}$ laser-induced ignition process.

A schematic diagram of the experimental setup for the application of time resolved tunable IR diode laser spectroscopy is shown in Fig. 6. For this experiment, a stainless steel cell equipped with edged $\mathrm{SrF}_{2}$ windows to avoid fringes in the monitoring diode laser beam was used. The $\mathrm{CH}_{3} \mathrm{OH}-\mathrm{O}_{2}$ mixtures were premixed; a small amount of $\mathrm{CO}$ was added and then stored in a glass bulb. Ignition was initiated by pulses of a Lumonics TEA $801 \mathrm{~A} \mathrm{CO}_{2}$ laser operating at the $9 P 20$ line at $\lambda=9.552 \mu \mathrm{m}$ in multimode oscillation. The laser light was focused with a concave spherical mirror along the axis of the reaction cell. With pulse energies up to $0.7 \mathrm{~J}$, mean fluences of $\sim 40 \mathrm{~J} / \mathrm{cm}^{2}$ were reached at the beam waist. With multimode laser operation, the fluence is fairly constant over the whole profile, neglecting statistical variations. Part of the laser radiation is coupled out in front of and behind the cell and measured by two pyroelectric energy detectors. Absorbed energies are calculated with regard to the reflectivity of the beam splitters and the cell windows 
and polarization of the laser light. Replacement of the previously used $\mathrm{KCl}$ by $\mathrm{SrF}_{2}$ windows was necessary since the $\mathrm{KCl}$ windows were damaged by the water formed in the oxidation of hydrogen containing fuels.

The mode-filtered diode laser beam was focused with a long focal distance $(>2 \mathrm{~m})$ into the explosion cell; the beam diameter at the entrance and exit windows was $\sim 1 \mathrm{~mm}$, and the distance to the $\mathrm{CO}_{2}$ laser beam could be varied between 9 and $18 \mathrm{~mm}$. Behind the cell, the diode laser beam is focused on the entrance slit of a second monochromator necessary to suppress the blackbody radiation of the burning gas mixture and then detected by a liquid nitrogen cooled $\mathrm{InSb}$ detector (SBRC). To provide a relative wavelength reference, a fraction of the diode laser beam was split off, and the transmission spectrum of a solid germanium etalon was recorded with a second InSb element (Judson Infrared). All detector signals were stored with a transient recorder (Krenz, TRC 6070) and laboratory computer for later data evaluation. Data acquisition started $3 \mathrm{~ms}$ before the trigger; i.e., the output of the first energy detector and the exact time of the laser pulse were extrapolated from the curve of the pyroelectric detector. The diode laser injection current was modulated with a $10-\mathrm{kHz}$ sawtooth current and a modulation amplitude corresponding to a scan range of $0.4 \mathrm{~cm}^{-1}$.

Well above the ignition limit a cylindrical symmetry in the flame front is attained in $\mathrm{CO}_{2}$ laser-induced ignition processes. ${ }^{14}$ In these conditions it is possible to monitor the propagation of the flame in the explosion cell by IR absorption techniques, integrating along the line of sight. With a monitoring IR laser beam parallel to the igniting $\mathrm{CO}_{2}$ laser beam, hence parallel to the flame front, temperature profiles with high spatial resolution can be obtained. The ratio of the line strengths of two distinct rovibrational absorption lines of an infrared active species is solely a function of temperature. By recording simultaneously the transmittance of these lines with a high repetition rate, the temperature of the gas can be measured with a high time resolution. The ratio $R$ of the logarithms of the line center transmittances $T$ of two equally broadened noninterfering lines is given by ${ }^{19}$

$$
R=\ln \left(T_{1}\right) / \ln \left(T_{2}\right) \approx S_{1} / S_{2} .
$$

The ratio of line strengths $S$ is a function of temperature alone and dominated by the Boltzmann distribution between the quantum states. From known relations follows

$$
S_{1} / S_{2}=\left[\left(v_{1}+1\right) m_{1} \exp \left(-E_{1} / k T\right)\right] /\left[\left(v_{2}+1\right) m_{2} \exp \left(-E_{2} / k T\right)\right],
$$

where $v$ and $J$ are the quantum numbers, $E$ is the energy of the lower state, $m$ is the rotational transition factor, $m=J+1$ for an $R$-branch transition, and $m=J$ for a $P$-branch transition of $C O$. Figure 7 shows recorded infrared absorption spectra of a typical single ignition event. The first trace is the transmittance spectrum of the added $\mathrm{CO}$ in the gas mixture at 2135.5 $\mathrm{cm}^{-1}$, just $50 \mu \mathrm{s}$ before the arrival of the flame front. The next traces give the spectra of the hot gas at the
Wavenumber

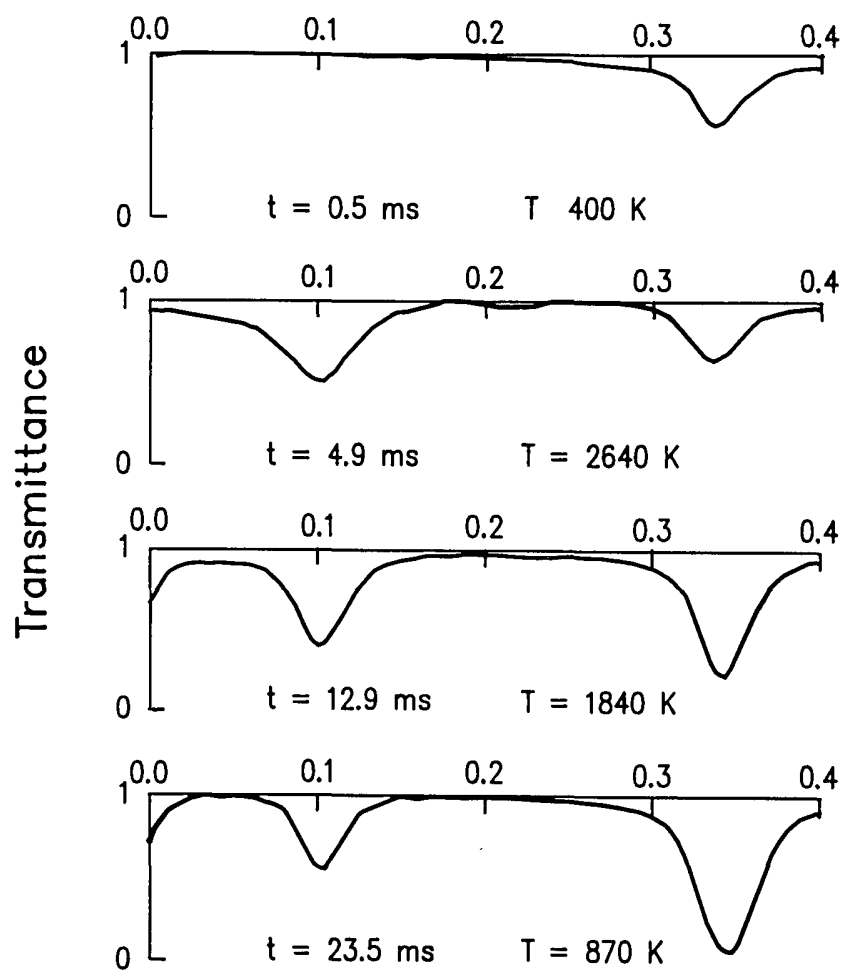

Fig. 7. Typical experimental transmittance spectra of the $\mathrm{CO}$ lines $1 R 4$ at $2135.3131 \mathrm{~cm}^{-1}$ (left) and $0 P 2$ at $2135.5466 \mathrm{~cm}^{-1}$ (right) during ignition and flame propagation. Indicated are the time delays from the laser pulse and the temperatures evaluated from the transmittance ratios.

indicated time after the ignition. The spectra have been linearized in a wavenumber with the simultaneously recorded etalon spectrum and corrected for the heavily sloped baseline that reflects the increasing output power of the diode laser with increasing current, unavoidable with this high scan rate and the homogeneous background absorption of the hot gases. Absorption in the higher vibrational level is negligible at room temperature but becomes significant at $600 \mathrm{~K}$ and dominates above $2000 \mathrm{~K}$.

The carbon monoxide itself takes part in the reaction; in a lean mixture it is rapidly consumed and in a fuel rich mixture, where the reactions are dominated by the methanol pyrolysis, it is one of the prominent products. Thus the initial pressure and CO concentration had to be carefully chosen to yield appropriate absorption levels throughout the measurement. In Fig. 8 the development of the temperature near the cell axis and near the cell wall after the ignition of a fuel rich mixture is displayed. Typical features common to all investigated ignition events were the sharply peaked increase in temperature within $<500 \mu \mathrm{s}$. The peak temperature decreases to the wall of the cell, reflecting the smaller amount of adiabatic compression heating, when most of the gas is already burnt. In 


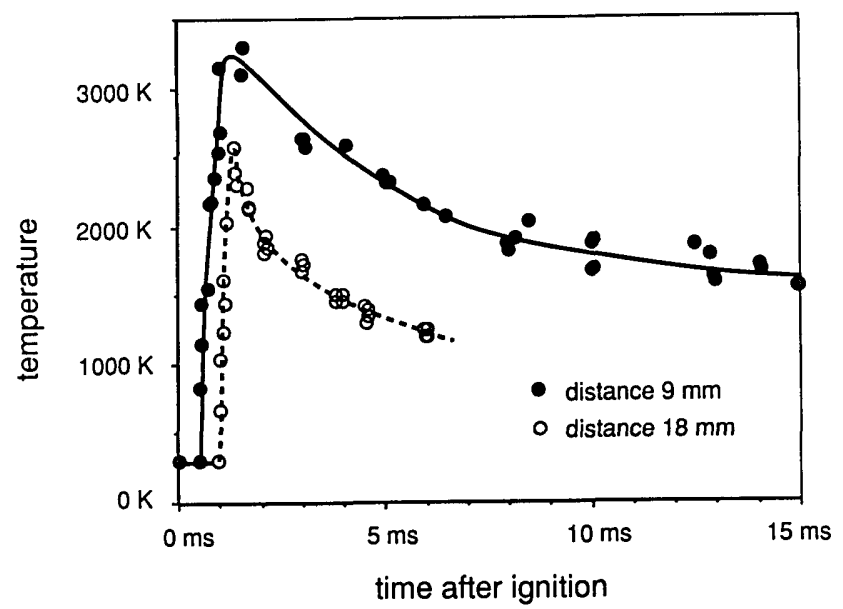

Fig. 8. Development of the temperature by the $\mathrm{CO}_{2}$ laser-induced ignition of a $\mathrm{CH}_{3} \mathrm{OH}(45 \%) / \mathrm{O}_{2}(50 \%) / \mathrm{CO}(5 \%)$ mixture in different distances from the ignition source.

this experiment the peak temperature near the cell axis was more than $3000 \mathrm{~K}$, near the cell wall to $2700 \mathrm{~K}$.

\section{OH Radical Concentration and Temperature Measurements in $\mathbf{C H}_{4}$-Air Counterflow Diffusion Flames}

Laminar counterflow diffusion flames constitute an important basis set for the simulation of turbulent combustion processes. Having a library of precalculated flamelets at different strain rates and fuel-oxidizer mixture compositions, the numerical treatment of turbulent flame structures may be reduced, e.g., with a flamelet model, ${ }^{23-25}$ to a problem that can be solved within a reasonable amount of time on existing computers. Therefore, there is renewed interest in the study of diffusion flames in a variety of different burning conditions to test and refine the validity of chemistry and transport properties used in modeling these flame structures. Among different types of counterflow diffusion flame the configuration where the flame is established in the forward stagnation region of a cylindrical porous burner offers some inherent advantages. This type of diffusion flame, extensively studied by Tsuji and co-workers, ${ }^{26}$ is ideally suited for experimental work for several reasons: strain rate and mixture composition can be adjusted easily; heat conduction problems are minimized because no rigid structures are in contact with the flame; and there is easy access to the flame front by intrusive and nonintrusive probing techniques. A comparison of data collected by intrusive methods ${ }^{27}$ with numerical modeling results of several groups is given in Ref. 28,

In previous papers ${ }^{29,30}$ we presented some comparisons between CARS temperature and concentration measurements and numerical modeling results. The disagreement between these results in the low strain rate regime stimulated us to improve and more closely match both the experimental and modeling approaches to this special flame structure.

The burner used in the experiments is similar in construction to the counterflow configuration used by Tsuji and co-workers. ${ }^{26,27}$ Methane-regulated by flow controllers-was ejected from a porous brass cylinder (pore size $\approx 20 \mu \mathrm{m}$ ) glued to a water cooled cylindrical copper support of $40-\mathrm{mm}$ diameter and 100 -mm length. The burner was installed in a vertically mounted wind tunnel with a square cross section at the burner head of $100 \times 100 \mathrm{~mm}$. Air was blown up the tunnel by four small fans.

A tunable KrF excimer laser (Lambda Physik EMG 150 TMSC) was used to excite single rotational lines of the $\left(v^{\prime}=3, v^{\prime \prime}=0\right)$ band in the $A^{2} \Sigma^{+}-X^{2} \Pi$ system of $\mathrm{OH} .{ }^{31}$ The laser beam was focused to a light sheet with a cross section of $10 \times 1 \mathrm{~mm}$ and was sent through the flame along the stagnation line (Fig. 9). A Nikon UV lens was used to image the fluorescence perpendicular to the light sheet onto a CCD camera (Proxitronic Nanocam II). Gate times of $20 \mathrm{~ns}$ completely suppressed flame emission and daylight. ${ }^{32}$ Besides $\mathrm{OH}$ fluorescence, which was only observed if the laser was tuned to an $\mathrm{OH}$ line, hydrocarbon fluorescence was detected which was independent of the excitation wavelength. The hydrocarbon emission spectrally

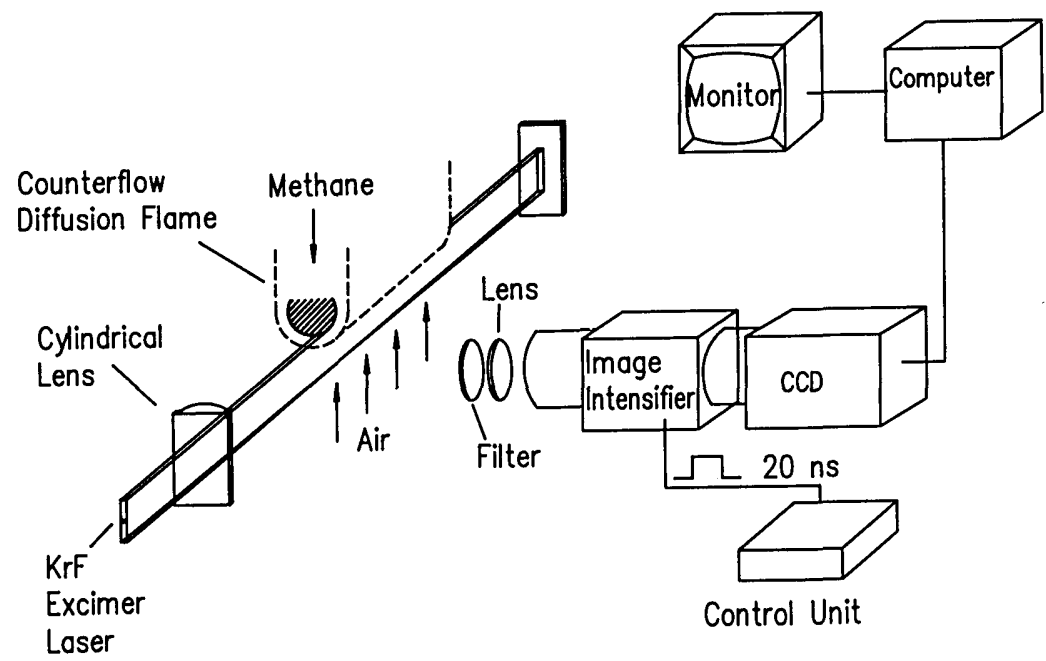

Fig. 9. Experimental setup for 2-D measurements of $\mathrm{OH}$ radical concentrations and temperatures in a counterflow diffusion flame. 


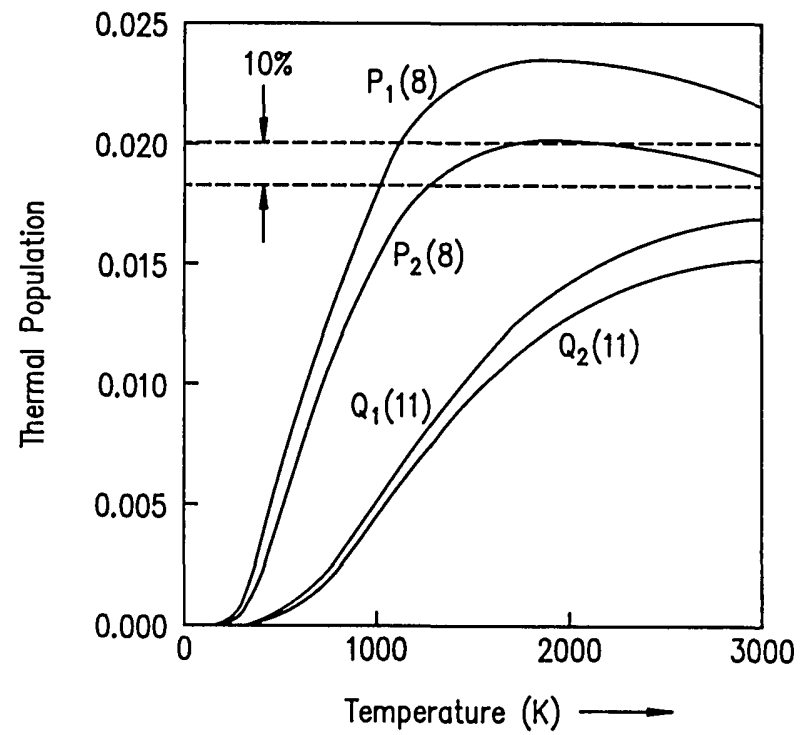

Fig. 10. Lower state population of several transitions of the $\mathrm{OH}$ radical as a function of temperature.

overlapped with the $\mathrm{OH}$ fluorescence and could, therefore, not be suppressed by the filters used (Schott UG11, WG 295). Two-dimensional LIF images of OH were obtained by recording images with the laser on and off resonance with an $\mathrm{OH}$ line and forming the difference. A hundred single images were averaged to obtain a sufficient SNR.

Several rotational lines of the 3-0 vibrational band of the $A^{2} \Sigma-X^{2} \Pi$ electronic transition of $\mathrm{OH}$ lie within the tuning range of the $\mathrm{KrF}$ laser, the strongest are $P_{1 /}$ ${ }_{2}(8)$ and $Q_{1 / 2}(11)$. The temperature dependence of the population of the lower states of these transitions is shown in Fig. 10. The $P_{1 / 2}(8)$ line is very attractive for concentration measurements: The population of the lower state changes by only $10 \%$ between 1300 and $3100 \mathrm{~K}$. The lifetime of the upper state is reduced due to predissociation to $\sim 100 \mathrm{ps}$ (Ref. 31) and, therefore, much shorter than the time for collisional quenching (around $2 \mathrm{~ns}$ as discussed below). The population of the initial states with higher rotational quantum numbers is strongly temperature dependent (Fig. 10). By division of two 2-D LIF images $S_{i}(x, y)(i=1,2)$ recorded successively with $P_{1}(8)$ and $Q_{1}(11)$ excitation, $2-D$ temperature fields $T(x, y)$ are derived from the equation

$$
\begin{aligned}
& T(x, y)= \\
& \frac{F_{2}-F_{1}}{k\left\{\ln \left[\frac{S_{1}(x, y)}{S_{2}(x, y)}\right]+\ln \left(\frac{B_{2} g_{2} Y_{2}}{B_{1} g_{1} Y_{1}}\right)+\ln \left[\frac{I_{2}(x, y)}{I_{1}(x, y)}\right]+\ln \left[\frac{\varepsilon_{2}(x, y)}{\varepsilon_{1}(x, y)}\right]\right\}} .
\end{aligned}
$$

$F$ and $g$ are the term value and statistical weight of the lower state, respectively, $k$ is the Boltzmann constant, $B$ is the Einstein coefficient, $I$ is the laser energy, $Y$ is the fluorescence quantum yield, and $\varepsilon$ is the detection efficiency. If the laser beam propagates along the $x$ direction, the beam profile $I(x, y)$ is independent of $x$ in

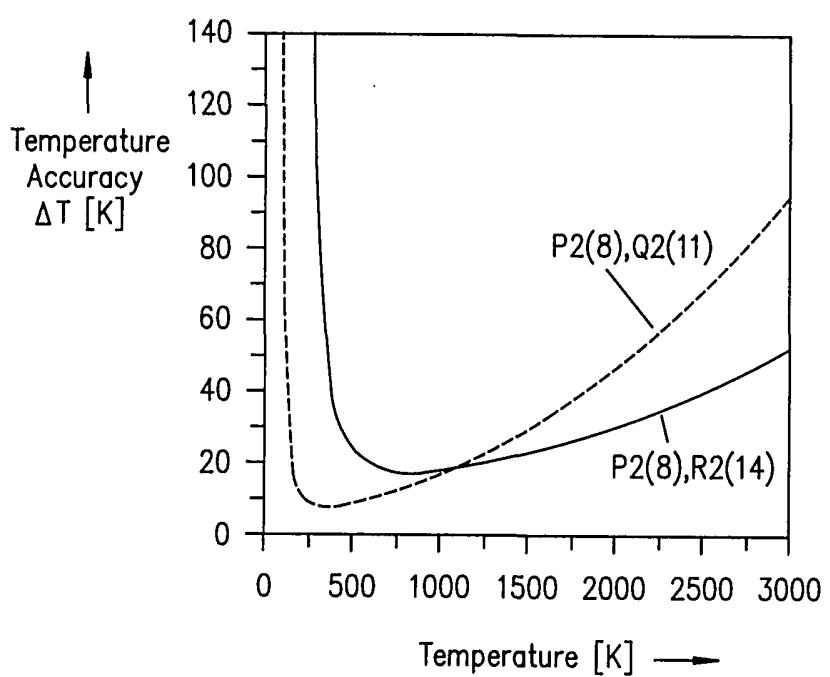

Fig. 11. Accuracy of the 2-D LIF temperature measurements (see text).

the case of negligible absorption. Since closely lying excitation and emission lines were used, the beam profiles $I_{i}$ and detection efficiencies $\varepsilon_{i}$ are equal.

Due to the excitation of predissociated states of the $\mathrm{OH}$ radical, the quantum yield is significantly reduced. By averaging over 100 shots signal intensities of $10^{4}$ photons/pixel could be generated. Figure 11 shows the accuracy of the temperature measurement for two different line pairs in these conditions as a function of temperature.

For the excitation of predissociating states, the ratio of the quantum yields is the ratio of the predissociation lifetimes, which are a property of the isolated $\mathrm{OH}$ molecule and can be determined by calibration. Such a calibration procedure also takes into account nonisotropic emission due to excitation with a (partly) polarized laser beam. ${ }^{31}$ Cattolica and Stephenson ${ }^{33}$ determined 2-D temperature fields in a similar way. Since they used two excitation lines with the same upper state, $Y_{1}$ and $Y_{2}$ were identical. The two further methods for 2-D temperature measurements demonstrated so far use only one excitation line and depend on a constant mole fraction of $\mathrm{O}_{2}{ }^{34}$ or NO. ${ }^{35}$

Figure 14 shows the 2-D temperature field of the counterflow diffusion flame. At one point the temperature was adjusted to the result of CARS measurements ${ }^{29,30}$ yielding the missing constant in Eq. (11).

Absolute $\mathrm{OH}$ radical concentrations have been determined with UV laser absorption measurements. As shown in Fig. 12, a pulsed frequency doubled dye laser (Lambda Physik FL 2002) pumped by an XeCl excimer laser (Lambda Physik EMG 201 MSC) was used to measure absorption spectra in the $A^{2} \Sigma^{+}-X^{2} \Pi$ $\left(v^{\prime \prime}=0, v^{\prime}=0\right)$ band of the $\mathrm{OH}$ radical. To obtain the spatial resolution necessary to resolve the flame structure, two pinholes ( $50 \mu \mathrm{m}$ in diameter) were used. The recording of stray light and flame emission was avoided by Schott filters (UG 11) and short gate times of the boxcar integrator. Lines of the $R$-bandhead near 307 


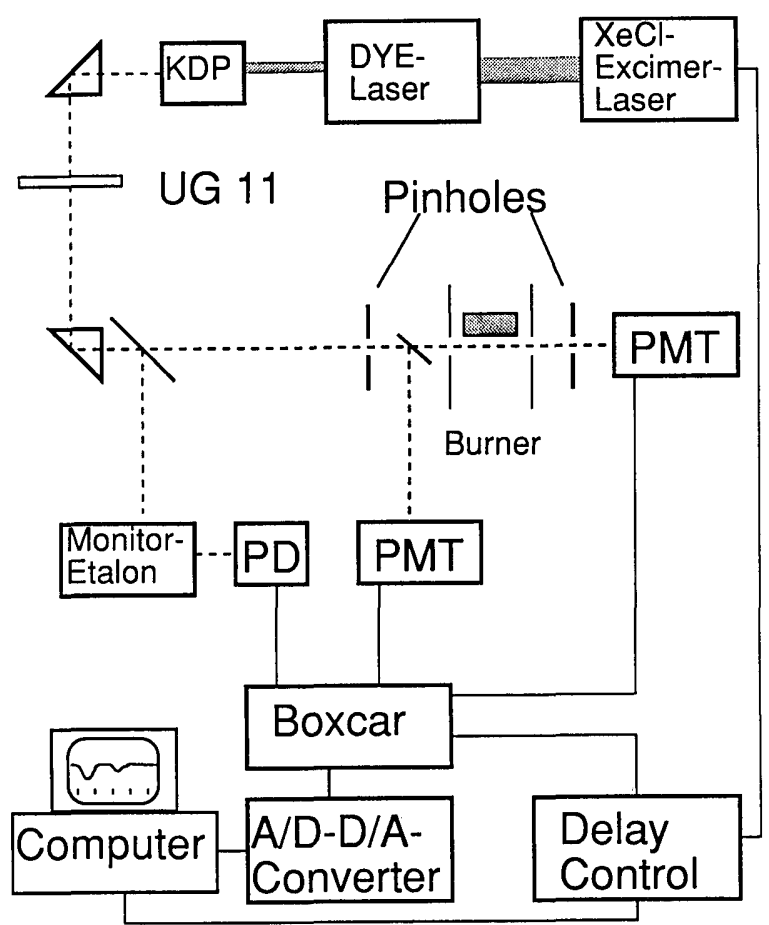

Fig. 12. Experimental arrangement for measuring UV absorption spectra of $\mathrm{OH}$ radicals with high spatial resolution in counterflow diffusion flames: KDP, frequency doubling crystal; PMT, photomultiplier tube; PD, photodiode.

nm were recorded, and synthetic spectra using published molecular data ${ }^{36,37}$ were fitted to these spectra to obtain rotational temperatures and absolute concentrations of $\mathrm{OH}$ radicals. The bandwidth of the laser was determined with a high resolution FabryPerot interferometer (Burleigh RC 140) and was taken into account in the calculations.

Figure 13 shows calculated ${ }^{38}$ and measured temperatures for a flame with a strain rate $a=125 \mathrm{~s}^{-1}$. The experimental temperature profiles (CARS, absorption, and 2-D LIF) differ in the location of their peaks. The difference is $<0.5 \mathrm{~mm}$ and due to a refractive index change across the flame. As observed experimentally, this effect is smaller for light beams perpendicular to the cylinder axis. Therefore, the absorption and CARS measurements have been shifted to the positions determined with 2-D LIF. Nevertheless, relative corrections of the positions as described earlier ${ }^{29}$ are unaffected by this procedure. The peak rotational temperature of $\mathrm{OH}$ was determined to be $1910 \mathrm{~K}$, compared with $1919 \mathrm{~K}$, measured with CARS. Each of these temperatures is lower than the $2023 \mathrm{~K}$ predicted by the calculations as shown in Fig. 13. However, heat losses to the burner surface were not included in the calculations.

For the $\mathrm{OH}$ concentration measurements, the effective absorption path length varying with the distance from the burner head was determined with 2-D LIF using the $\mathrm{OH}$ fluorescence image (Fig. 14) to account for edge effects. The peak $\mathrm{OH}$ radical concentration

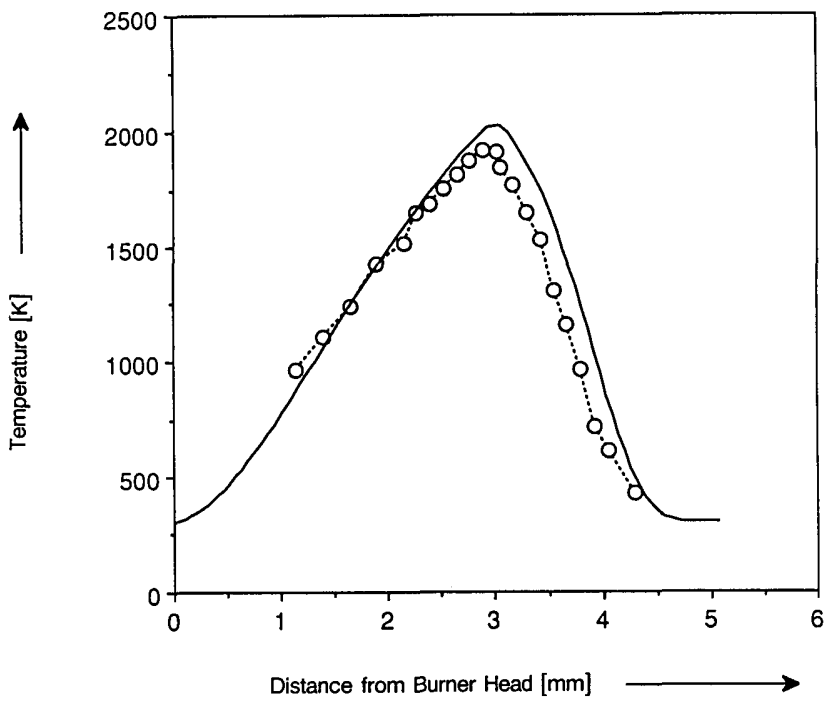

Fig. 13. Temperature profile in a counterflow diffusion flame $\left(a=125 \mathrm{~s}^{-1}, v_{\mathrm{CH} 4}=11,4 \mathrm{~cm} / \mathrm{s}\right) ; 0$, measurement (CARS), $\longrightarrow$, simulation.

determined with the absorption measurements is 1.75 times higher than the concentration calculated with the model. The absolute concentration profile of Fig. 15 was obtained by calibrating relative concentrations from 2-D LIF measurements with the peak concentration of the absorption measurements. Again, the peak predicted by the model is too far on the air side of the flame. Although the model has been improved ${ }^{38}$ there are still deviations between experiment and calculations due possibly to shortcomings in the transport model, especially for small molecules.

LIF measurements of temperature and species concentration are not strongly affected by collisional effects if predissociating states are excited. However, not all molecules relevant for combustion diagnostics have suitable predissociating states. If the lifetime due to radiation and predissociation is greater than the particle collision times, information on quenching and relaxation is needed to correct measured intensities. We investigate these effects in atmospheric pressure flames directly by determining the effective lifetimes with a picosecond laser and fast detection techniques.

The distributed feedback dye laser system employed for this work (Fig. 16) has been described previously. ${ }^{39-41}$ The size of the oscillator has been much reduced compared with our previous work, lowering the requirements for pump beam quality and improving the laser pulse/ASE ratio. ${ }^{42}$ The laser is tuned by (a) adjusting the refractive index of the dye solution and (b) rotation and/or translation of the oscillator mirrors. If the DFDL is pumped just over threshold, single pulses are obtained, so that pulse selection is dispensed with.

A BBO crystal was used for frequency doubling, and the UV pulse was separated from the fundamental by a quartz prism. Pulses of appropriate wavelength with 25-30 ps FWHM and spectral width of $1-2 \mathrm{~cm}^{-1}$ were 


\section{$z[\mathrm{~mm}]$}

75

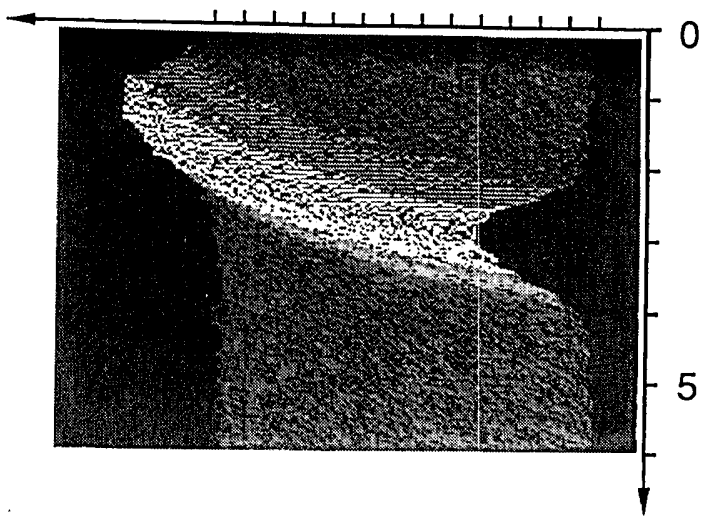

$6000 \quad 0$

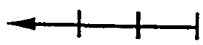

Absolute $\mathrm{OH}$ concentration [ppm]

$z[\mathrm{~mm}]$

75

65
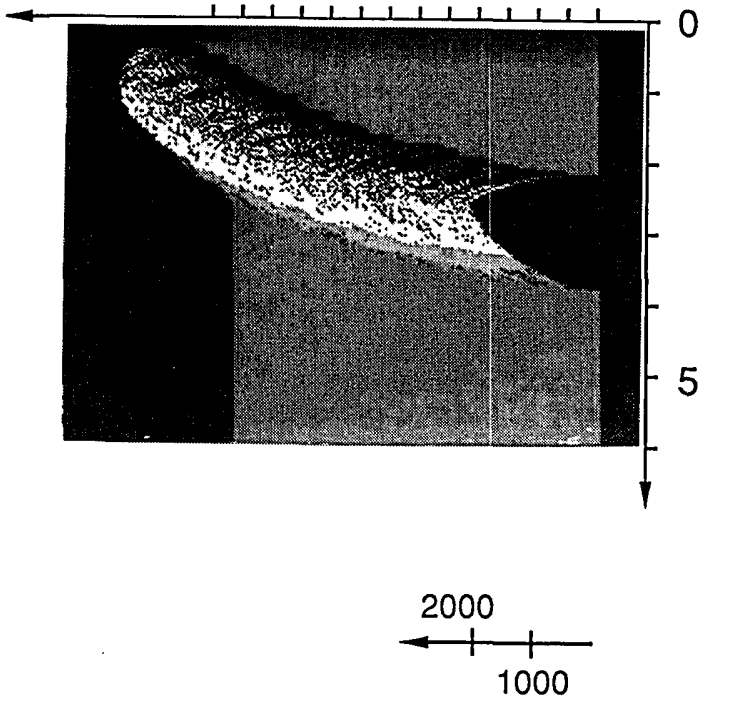

Temperature [K]

Fig. 14. Absolute 2-D OH radical concentration and temperature distribution in a $\mathrm{CH}_{4}$ air counterflow diffusion flame $\left(a=125 \mathrm{~s}^{-1}\right.$, $\left.v_{\mathrm{CH} 4}=11.4 \mathrm{~cm} / \mathrm{s}\right)$, imaged after excitation of the (3-0) vibrational band of the $A-X$ system with a tunable $\mathrm{KrF}$ excimer laser, detected with an image intensified CCD camera and calibrated with absorption measurements.

used to excite $\mathrm{OH}$ radicals. Pulse energies used were $2-3 \mu \mathrm{J}$ for $(0-0)$ excitation and $\sim 10 \mu \mathrm{J}$ for (1-0) excitation. The UV laser beam was directed into the counterflow diffusion burner; integrated fluorescence was observed at right angles to the focused laser beam. Broadband fluorescence light was focused onto the 15-

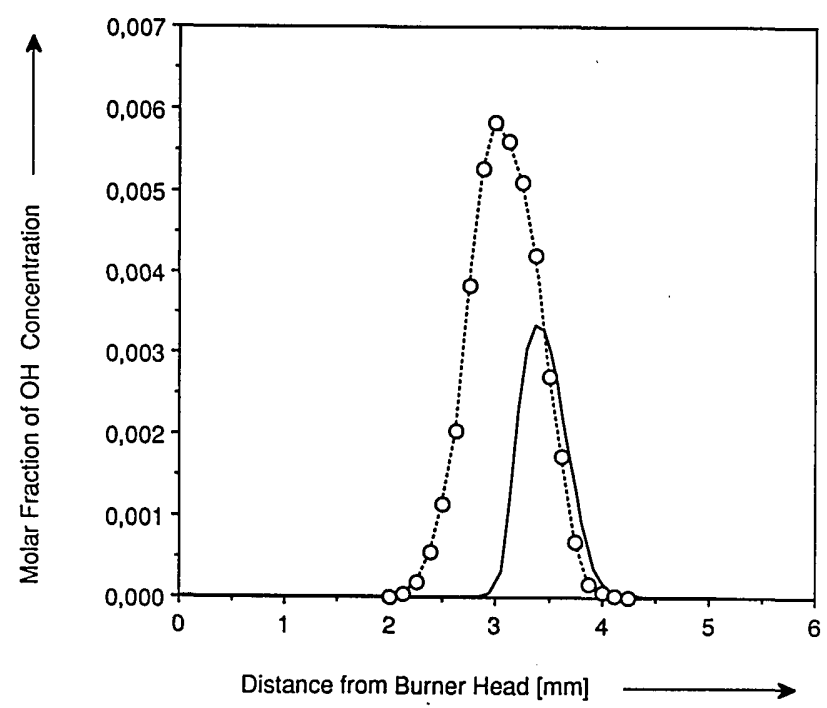

Fig. 15. Absolute $\mathrm{OH}$ radical concentration profile in a counterflow diffusion flame $\left(a=125 \mathrm{~s}^{-1}, v_{\mathrm{CH} 4}=11.4 \mathrm{~cm} / \mathrm{s}\right) ; 0$, absorption and light sheet measurements, _, simulation.

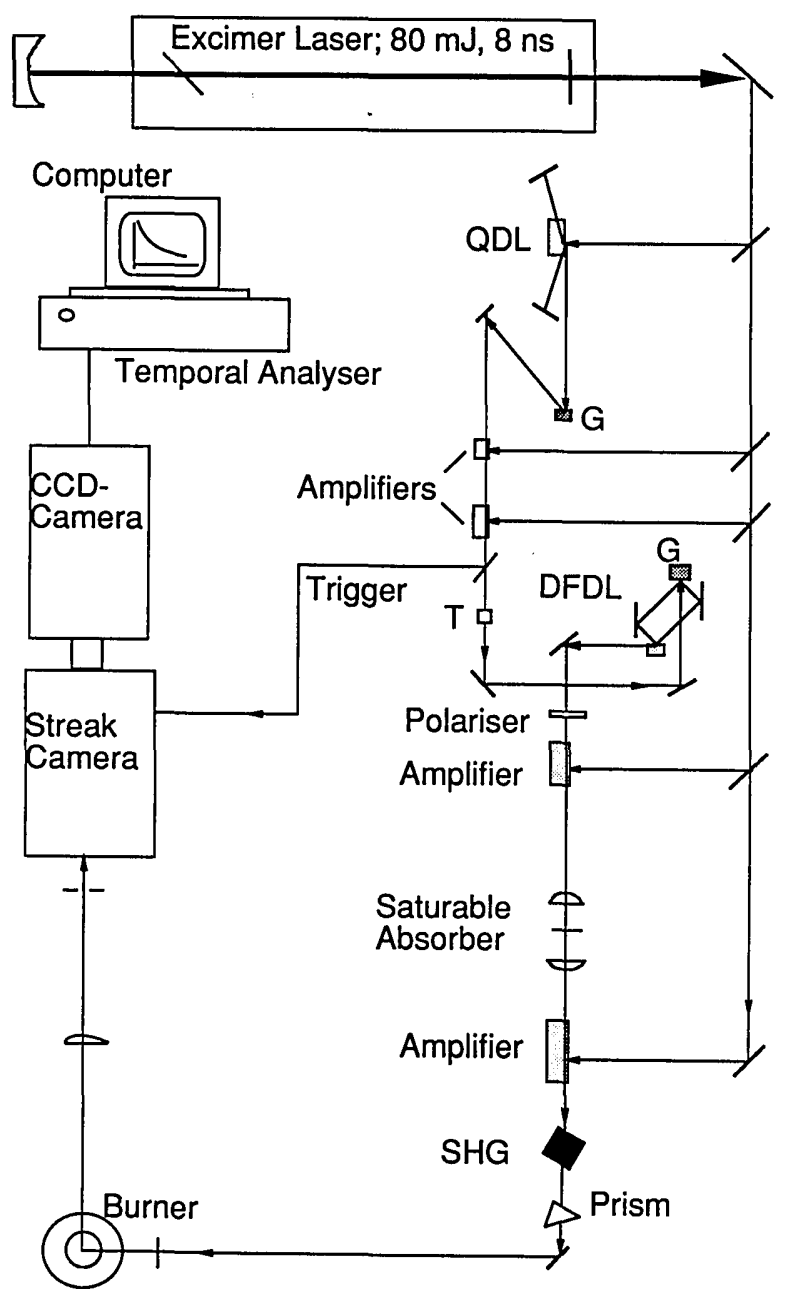

Fig. 16. Experimental setup for fluorescence lifetime measurements in atmospheric pressure flames: $\mathrm{QDL}$, quench dye laser; DFDL, distributed feedback dye laser; $G$, holographic grating; $T$, beam translation prism; SHG, frequency doubler. 


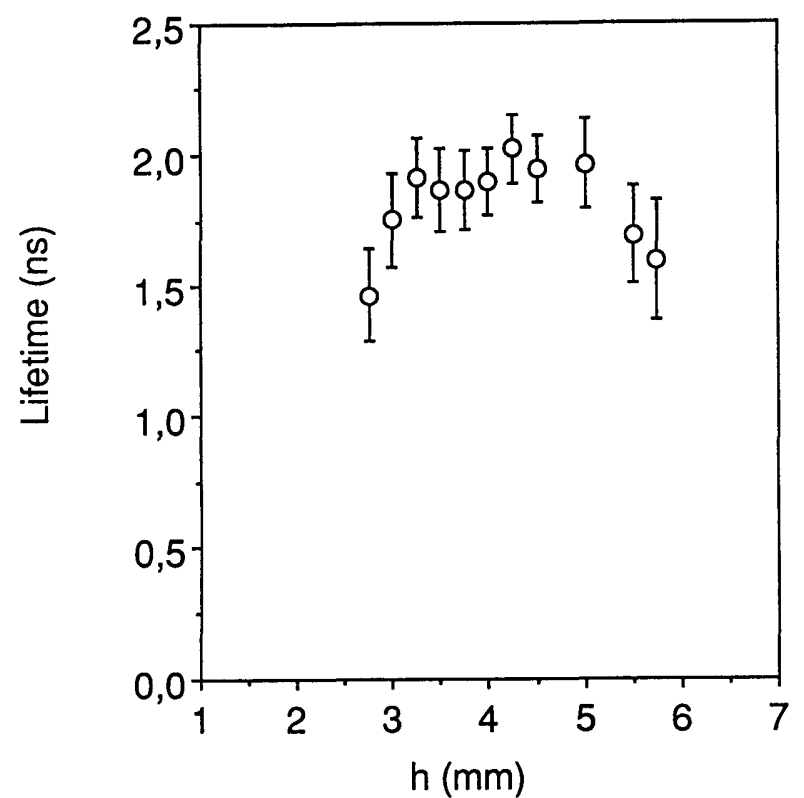

Fig. 17. Dependence of $\mathrm{OH}\left(A^{2} \Sigma^{+}, v^{\prime}=0\right)$ lifetime on the height above the burner head in an atmospheric pressure $\mathrm{CH}_{4}$-air counterflow diffusion flame $\left(a=15 \mathrm{~s}^{-1}, v_{\mathrm{CH} 4}=1.6 \mathrm{~cm} / \mathrm{s}\right)$.

mm slit of a streak camera (C1587 Hamamatsu, S-20 photocathode) gated to exclude flame emission and a streak time of $10-\mathrm{ns} / 15-\mathrm{mm}$ set. The data were interpreted by a temporal analyzer (Hamamatsu C2200).

Fluorescence from wavelength regions outside that of the $\mathrm{OH}$ bands of interest was excluded by inserting suitable filters. The SIT camera used previously ${ }^{39-41}$ to read out signals from the streak camera has now been replaced by a charged-coupled device (CCD) camera (C3140 Hamamatsu). ${ }^{42}$ The CCD camera allows much more efficient collection of fluorescence data (routine recording with repetition rates of $10 \mathrm{~Hz}$ or more) as well as detection of a more weakly fluorescing species. Also, the laser was found to run with higher stability at the faster repetition rate.

As shown in Fig. 17, the longest lifetimes ( 2 ns) were found in the region of maximum temperature $(\sim 1980 \mathrm{~K})$, while shorter values are found on either side of the temperature maximum. The observed variation in lifetime is a result of the decreasing (a) density and (b) quenching efficiencies with increasing temperature. However, the formation of water vapor in the flame front partly compensates these effects, because it quenches the $\mathrm{OH}$ fluorescence particularly strongly.

\section{Two-Dimensional Light Sheet Diagnostics in a Diesel Engine}

In recent years, there has been growing activity in fundamental research of combustion processes in internal combustion engines. Because of increasing air pollution and decreasing petrol resources, there is a strong need for further optimization of internal com-
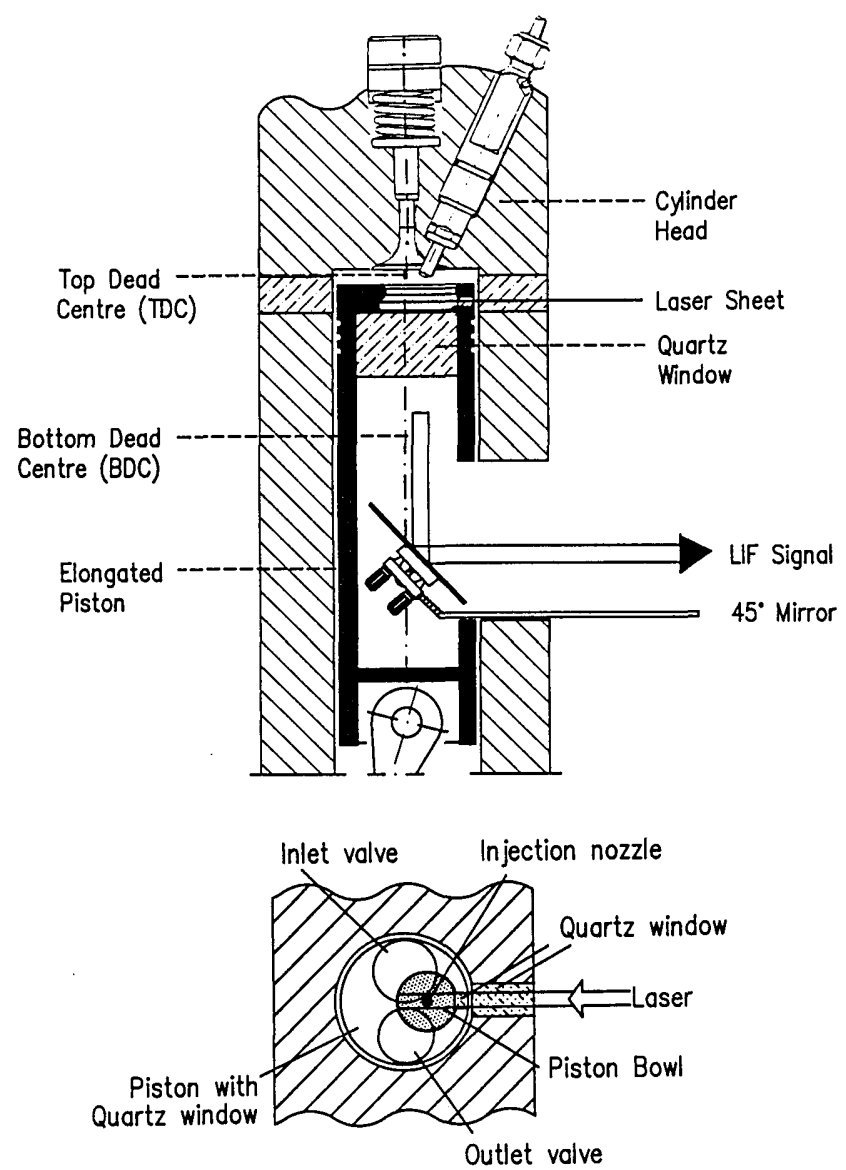

Fig. 18. Optical access of the transparent Volkswagen diesel engine for light sheet diagnostics.

bustion engines. In addition to developments pursued by engineers, there are more fundamental approaches by detailed investigation of the chemical and transport processes in turbulent combustion. This task requires numerical simulations of the relevant processes and verification by experimental methods of combustion diagnostics.

In contrast to conventional photographic techniques, which integrate along the line of sight, laser light sheet techniques yield 2-D images with high spatial resolution. Two-dimensional Mie scattering $43-45$ and 2-D LIF ${ }^{32,46-49}$ were successfully applied to the study of combustion in premixed-charge engines. Diesel combustion is considerably more complex. Besides flame propagation, fuel injection, spray formation, atomization, vaporization, and autoignition have to be investigated. Two-dimensional light sheet measurements were performed for spray visualization by either Mie scattering ${ }^{46,50}$ or exciplex fluorescence. ${ }^{51-53}$ The latter allows the simultaneous observation of liquid and vapor. Allen and Hanson investigated spray flames by $\mathrm{LIF}$ of $\mathrm{OH}, \mathrm{CH}$, and fuel vapor. ${ }^{54,55}$

In the present work, the 2-D light sheet technique is applied to a realistic four-cylinder DI diesel engine operated with real diesel fuel. The transparent diesel 


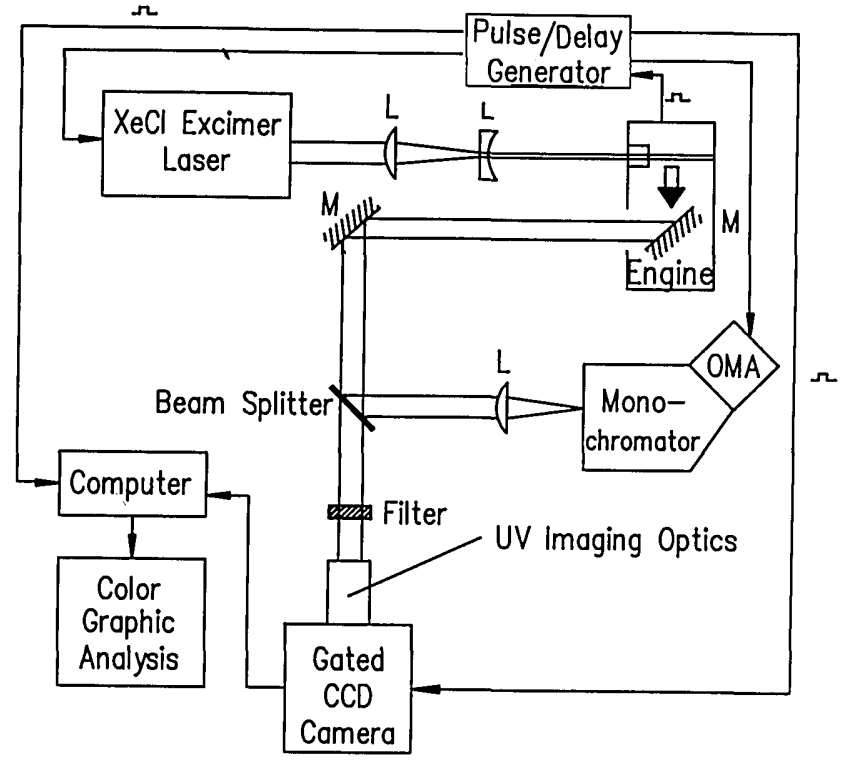

Fig. 19. Experimental setup for 2-D LIF at the transparent diesel engine: $L$, lens; $M$, mirror.

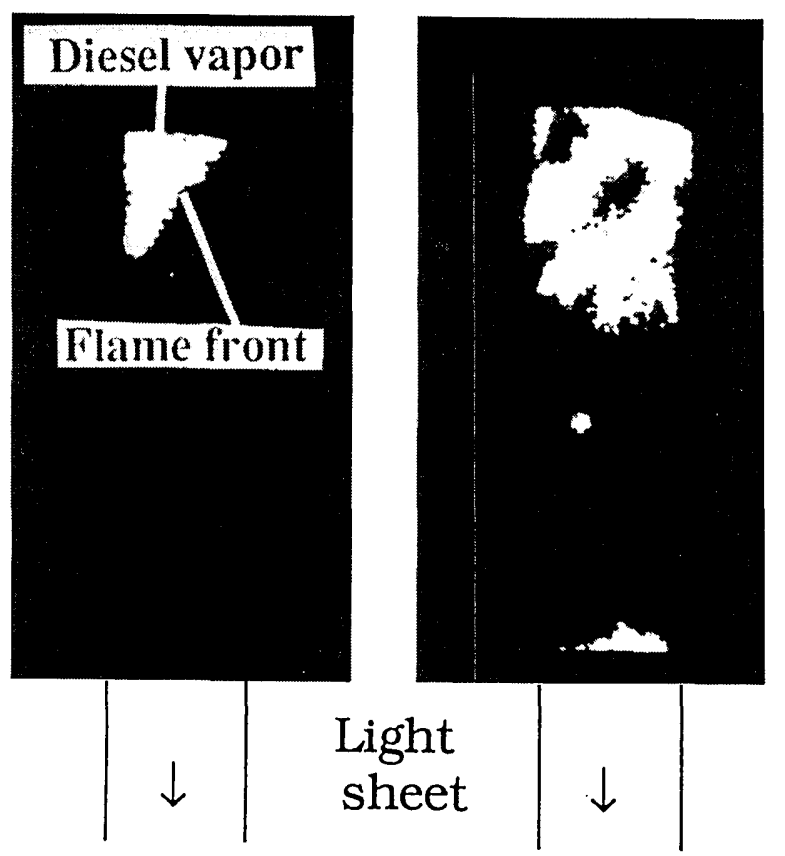

Fig. 20. Two-dimensional Mie scattering for visualization of fuel injection through a five-hole nozzle.

engine was constructed by Volkswagen AG and is mainly composed of series parts. ${ }^{56,57}$ The fuel is directly injected into a bowl-in-piston chamber through a five-hole nozzle. The laser light sheet enters through quartz windows in the cylinder wall and piston. A third quartz window in the bottom of the piston bowl, elongated pistons, and an intermediate housing between the crankcase and cylinder head allow observation of the fluorescence (Fig. 18).

The experimental setup for 2-D LIF diagnostics is

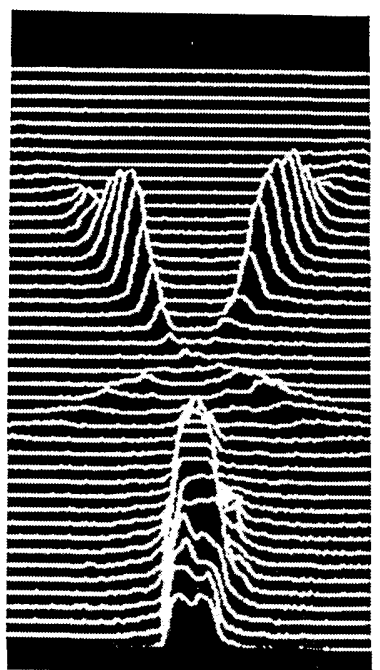

Light sheet

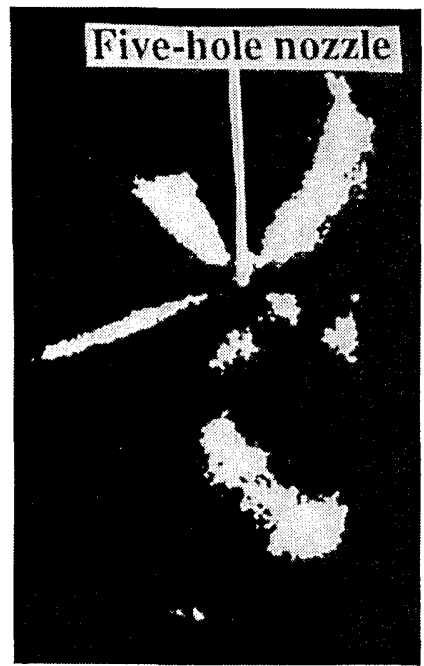

Swirl influence

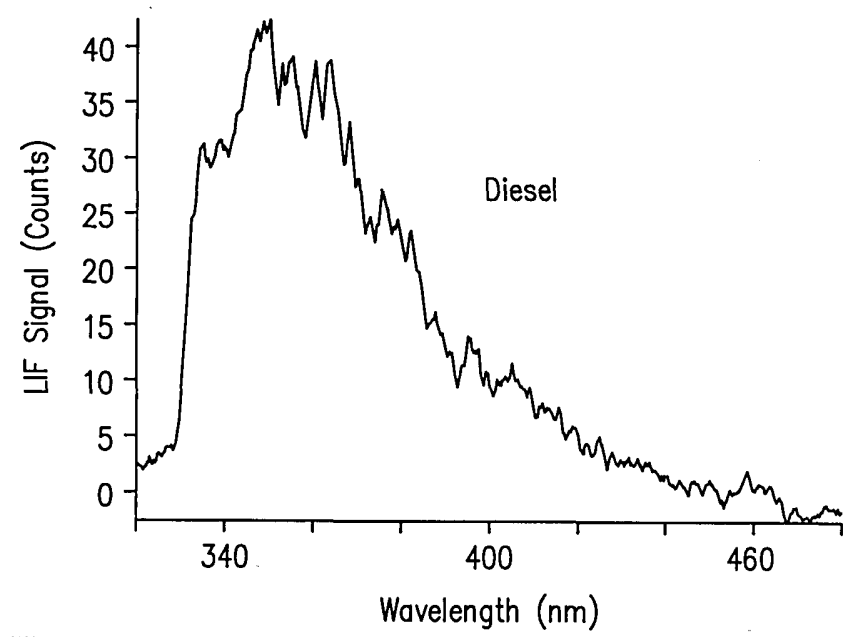

Fig. 22. Single shot emission spectrum of diesel fuel excited by a $\mathrm{XeCl}$ excimer laser.

shown in Fig. 19. The beam of a $\mathrm{XeCl}$ excimer laser was shaped with cylindrical lenses into a light sheet of $1 \mathrm{~mm}$ in height and $10 \mathrm{~mm}$ in width, corresponding to the diameter of the piston window. The fluorescence was imaged onto an image-intensified CCD camera and onto a monochromator with an OMA system for the accumulation of single shot spectra. The monochromator had a grating with 300 lines $/ \mathrm{mm}$, which allowed a spectral range of $200 \mathrm{~nm}$ to be observed with the OMA detector. By operating the image intensifiers of the CCD camera (20 ns) and the OMA (100 ns) with short gate times, flame emission was completely 
suppressed. First experiments aimed to visualize the fuel jets by Mie scattering. Since the small window in the piston did not allow optical access to the fuel spray, these experiments were performed at $40^{\circ} \mathrm{ATDC}$, when optical access was possible up to the region above the piston. On the left-hand side of Fig. 20, only three of the five fuel jets are directly illuminated by the light sheet. The spray could be visualized inside the piston bowl by laser light scattered from the windows and the piston wall. The right-hand side of Fig. 20 shows the swirl influence for a small quantity of injected fuel. The Mie scattering experiments were performed with $n$-heptane, because this fuel allowed operation for several minutes without fouling the windows.

With diesel fuel, the situation differed drastically. After a few seconds, all windows were black with soot. Only with our single shot capability (prior adjustment of laser and detection system) was acquisition of single shot spectra with an OMA system possible.

Figure 21 was obtained shortly after ignition. The unburnt fuel is seen by the diesel fuel fluorescence shown in Fig. 22, whereas in the dark regions the fuel is already burnt. The emission spectrum of laser excited fuel was taken with the OMA (Fig. 22). The spectrum was acquired with a single laser pulse. To avoid interference with laser stray light, a dielectric mirror, which has a reflectivity of $99 \%$ at $308 \mathrm{~nm}$ and $80 \%$ transmission for $\lambda>330 \mathrm{~nm}$, was placed in front of the entrance slit of the monochromator.

These first measurements with the transparent Volkswagen diesel engine have clearly demonstrated the feasibility of 2-D LIF diagnostics in a realistic diesel engine. The fluorescence signals were high enough to record single shot emission spectra, which could help to identify the laser excited species.

We would like to thank J. Warnatz, F. Behrendt, and U. Maas for interesting and stimulating discussions on the modeling of combustion systems. We gratefully acknowledge the financial support of the Deutsche Forschungsgemeinschaft (SFB123), the Bundesministerium fur Forschung und Technologie, and Land Baden-Wurttemberg for the research association TECFLAM. The diesel research was financed by the Commission of the European Communities within the frame of the JOULE program and by the Joint Research Committee of European automobile manufacturers (Fiat, Peugeot SA, Renault, Volkswagen, and Volvo) and the Swedish National Board for Technical Development within the IDEA program.

\section{References}

1. R. K. Lyon, "Method for the reduction of the concentration of NO in combustion effluence using ammonia," U.S. Patent 3,900,554 (1975).

2. M. Gehring, K. Hoyermann, H. J. Schacke, and J. Wolfrum, "Direct Studies of Some Elementary Steps for the Formation and Destruction of Nitric Oxide in the H-N-O-System," in Fourteenth International Symposium on Combustion (Combustion Institute, Pittsburgh, 1973), pp. 99-105.

3. F. Allario and R. K. Seals, Jr., "Measurements of $\mathrm{NH}_{3}$ Absorption Coefficients with a ${ }^{13} \mathrm{C}^{16} \mathrm{O}_{2}$ Laser," Appl. Opt. 14, 2229-2233 (1975).
4. A. Kaldor and R. L. Woodin, "Applications of Lasers to Chemical Processing," Proc. IEEE 70, 565-578 (1982).

5. J. Wolfrum, "Chemische Elementarprozesse bei der Bildung und Beseitigung von Schadstoffen in Verbrennungsvorgängen," TECFLAM Seminar 1, 7-21 (1985).

6. F. Janssen, F. v. d. Kerkhof, J. B. Lefers, P. Lodder, and L. J. Luierweert, "The Determination of Ammonia in Flue Gas from the Selective Catalytic Reduction of Nitric Oxide with Ammonia," Anal. Chim. Acta 190, 245-254 (1986).

7. H. Wolf and W. J. Riedel, " $\mathrm{NH}_{3}$-Measurements in Power Plants with DeNOx Installations," in Monitoring of Gaseous Pollutants by Tunable Diode Lasers, R. Grisar, H. Preier, G. Schmidtke, and G. Restelli, Eds. (Reidel, Dordrecht, The Netherlands, 1987), pp. 120-126.

8. K. Gregorius and H. Schorner, "Stack Gas Control by Diode Laser Spectrometer in Power Plants," in Monitoring of Gaseous Pollutants by Tunable Diode Lasers, R. Grisar, H. Preier, G. Schmidtke, and G. Restelli, Eds. (Reidel, Dordrecht, The Netherlands, 1987), pp. 127-133.

9. H. Neckel and J. Wolfrum, "IR Diode Laser Measurements of the $\mathrm{NH}_{3}\left(\nu_{2}\right)$ Band at Different Temperatures," Appl. Phys. B 49, 85-89 (1989).

10. F. W. Taylor, "Spectral Data for the $\nu_{2}$ Bands of Ammonia with Applications to Radiative Transfer in the Atmosphere of Jupiter," J. Quant. Spectrosc. Radiat. Transfer 13, 1181-1217 (1973).

11. L. S. Rothman et al., "AFGL Trace Gas Compilation: 1982 Version," Appl. Opt. 22, 1616-1627 (1983).

12. A. Stein, T. R. Todd, and B. N. Perry, "Carbon Dioxide Laser Monitor for $\mathrm{NH}_{3}$ in Flue Gas,” Appl. Opt. 22, 3378-3381 (1983).

13. U. Maas, B. Raffel, J. Wolfrum, and J. Warnatz, "Observation and Simulation of Laser Induced Ignition Processes in $\mathrm{O}_{2}-\mathrm{O}_{3}$ and $\mathrm{H}_{2}-\mathrm{O}_{2}$ Mixtures," in Twenty-First International Symposium on Combustion (Combustion Institute, Pittsburgh, 1986), pp. 1869-1876.

14. B. Raffel and J. Wolfrum, "Spatial and Time Resolved Observation of $\mathrm{CO}_{2}$-Laser Induced Explosions of $\mathrm{O}_{2} / \mathrm{O}_{3}$ Mixtures in Cylindrical Cells," Z. Phys. Chem. Neue Folge 161,43-59 (1989).

15. B. Raffel and J. Wolfrum, "Infrared Laser Induced Ignition of Gas Mixtures," Ber. Bunsenges. Phys. Chem. 90, 997-1001 (1986).

16. U. Maas and J. Warnatz, "Simulation of Thermal Ignition Processes in Two-Dimensional Geometries," Z. Phys. Chem. Neue Folge 161, 61-81 (1989).

17. R. K. Hanson and P. K. Falcone, "Temperature Measurement Technique for High-Temperature Gases Using a Tunable Diode Laser," Appl. Opt. 17, 2477-2480 (1978).

18. S. M. Schoenung and R. K. Hanson, "Temporally and Spatially Resolved Measurements of Fuel Mole Fraction in a Turbulent CO Diffusion Flame," in Nineteenth International Symposium on Combustion (Combustion Institute, Pittsburgh, 1982), pp. 449-458.

19. B. Rosier, P. Gicquel, D. Henry, and A. Coppale, "Carbon Monoxide Concentrations and Temperature Measurements in a Low Pressure $\mathrm{CH}_{4}-\mathrm{O}_{2}-\mathrm{NH}_{3}$ Flame," Appl. Opt. 27, 360-364 (1988).

20. H. Kanamori, J. E. Buttler, K. Kawaguchi, K. C. Yamada, and E. Hirota, "Infrared Diode Laser Kinetic Spectroscopy of Transient Molecules Produced by Excimer Laser Photolysis: Application to the SO Radical," J. Mol. Spectrosc. 113, 262-268 (1985).

21. P. H. Beckwith, C. E. Brown, D. J. Dannagher, D. R. Smith, and J. Reid, "High Sensitivity Detection of Transient Infrared Absorption Using Tunable Diode Lasers," Appl. Opt. 26, 26432649 (1987).

22. D. T. Cassidy and J. Reid, "High-Sensitivity Detection of Trace Gases Using Sweep Integration and Tunable Diode Lasers," Appl. Opt. 21, 2527-2530 (1982). 
23. F. A. Williams, "Turbulent Mixing in Non-Reactive and Reactive Flows," in "Complex Chemical Reaction Systems," S. N. B. Murphy, Ed. (Plenum, New York, 1975), p. 189.

24. K. N. C. Bray, "“"Recent Advances in Theoretical Descriptions of Turbulent Diffusion Flames," in Book, Springer Series in Chemical Physics, Vol. 47, J. Warnatz and W. Jager, Eds. (SpringerVerlag, Berlin, 1987), pp. 356-375.

25. N. Peters, "Laminar Flamelet Concepts in Turbulent Combustion," in Twenty-First International Symposium on Combustion (The Combustion Institute, Pittsburgh, 1986), pp. 12311250.

26. H. Tsuji, "Counterflow Diffusion Flames," Prog. Energy Com. bust. Sci. 8, 93-119 (1982).

27. H. Tsuji and I. Yamaoka, "Structure Analysis of Counterflow Diffusion Flames in the Forward Stagnation Region of a Porous Cylinder," in Thirteenth International Symposium on Combustion (Combustion Institute, Pittsburgh, 1971), pp. 723-731.

28. G. Dixon-Lewis et al., "Calculation of the Structure and Extinction Limit of a Methane-Air Counterflow Diffusion Flame in the Forward Stagnation Region of a Porous Cylinder," in Twentieth International Symposium on Combustion (The Combustion Institute, Pittsburgh, 1984), pp. 1893-1904.

29. T. Dreier, B. Lange, J. Wolfrum, M. Zahn, F. Behrendt, and J. Warnatz, "CARS Measurements and Computations of the Structure of Laminar Stagnation-Point Methane-Air Counterflow Diffusion Flames," in Twenty-First International Symposium on Combustion (Combustion Institute, Pittsburgh, 1986), pp. 1729-1736.

30. T. Dreier, B. Lange, J. Wolfrum, M. Zahn, F. Behrendt, and J. Warnatz, "Comparison of CARS Measurements and Calculations of the Structure of Laminar Methane-Air Counterflow Diffusion Flames," Ber. Bunsenges. Phys. Chem. 90, 1010-1015 (1986).

31. P. Andresen, A. Bath, W. Groger, H. W. Lulf, G. Meijer, and J. J. ter Meulen, "Laser-Induced Fluorescence with Tunable Excimer Lasers as a Possible Method for Instantaneous Temperature Field Measurements at High Pressures: Checks with an Atmospheric Flame," Appl. Opt. 27, 365-378 (1988).

32. R. Suntz, H. Becker, P. Monkhouse, and J. Wolfrum, "TwoDimensional Visualization of the Flame Front in an Internal Combustion Engine by Laser-Induced Fluorescence of OH Radicals," Appl. Phys. B 47, 287-293 (1988).

33. R. J. Cattolica and D. A. Stephenson, "Two-Dimensional Imaging of Flame Temperature Using Laser-Induced Fluorescence," Prog. Astronaut. Aeronaut. 95, 714-721 (1985).

34. M. P. Lee, P. H. Paul, and R. K. Hanson, "Quantitative Imaging of Temperature Fields in Air Using Planar Laser-Induced Fluorescence of $\mathrm{O}_{2}$," Opt. Lett. 12, 75-77 (1987).

35. J. M. Seitzman, G. Kychakoff, and R. K. Hanson, "Instantaneous Temperature Field Measurements Using Planar-Induced Fluorescence," Opt. Lett. 10, 439-441 (1985).

36. G. H. Dieke and H. M. Crosswhite, "The Ultraviolet Bands of OH: Fundamental Data," J. Quant. Spectrosc. Radiat. Transfer 2, 97-199 (1962).

37. A. Goldman and J. R. Gillis, "Spectral Line Parameters for the $A^{2} \Sigma-X^{2} \Pi(0,0)$ Band of $\mathrm{OH}$ for Atmospheric and High Temperatures," J. Quant. Spectrosc. Radiat. Transfer 25, 111-135 (1981):

38. F. Behrendt, "Simulation laminarer Gegenstrom-Diffusionsflammen unter Verwendung detaillierter Reaktionsmechanismen," Dissertation, U. Heidelberg (1989).
39. R. Schwarzwald, P. Monkhouse, and J. Wolfrum, "Picosecond Fluorescence Lifetimes Measurement of the OH Radical in an Atmospheric Pressure Flame," Chem. Phys. Lett. 142, 15-18 (1987).

40. R. Schwarzwald, P. Monkhouse, and J. Wolfrum, "Fluorescence Studies of $\mathrm{OH}$ and $\mathrm{CN}$ Radicals in Atmospheric Pressure Flames Using Picosecond Excitation," in Twenty-Second International Symposium on Combustion (Combustion Institute, Pittsburgh, 1988), pp. 1413-1420.

41. R. Schwarzwald, P. Monkhouse, and J. Wolfrum, "Fluorescence Lifetimes for Nitric Oxide in Atmospheric Pressure Flames Using Picosecond Excitation," Chem. Phys. Lett. 158, 60-64 (1989).

42. M. Kollner, P. Monkhouse, and J. Wolfrum, "Time-Resolved LIF of $\mathrm{OH}\left(A^{2} \Sigma \mathrm{v}^{\prime}=1\right.$ and $\left.\mathrm{v}^{\prime}=0\right)$ in Atmospheric Pressure Flames Using Picosecond Excitation," Chem. Phys. Lett. 168, $355-360$ (1990).

43. A. O. zur Loye and F. V. Bracco, "Two-Dimensional Visualization of Premixed-Charge Flame Structure in an IC Engine," SAE Paper 870454 (1988).

44. T. A. Baritaud and R. M. Green, "A 2-D Flame Visualization Technique Applied to the I.C. Engine," SAE Paper 860025 (1986).

45. G. F. W. Ziegler, A. Zettlitz, P. Meinhardt, R. Herweg, R. Maly, and W. Pfister, "Cycle-Resolved Two-Dimensional Flame and Flow Visualization in a Spark-Ignition Engine," SAE Paper 881634 (1988).

46. F. W. Schipperijn, R. Nagasaka, R. F. Sawyer, and R. M. Green, "Imaging of Engine Flow and Combustion Processes," SAE Paper 881631 (1988).

47. P. G. Felton, J. Mantzaras, D. S. Bomse, and R. L. Woodin, "Initial Two-Dimensional Laser Induced Fluorescence Measurements of OH Radicals in an Internal Combustion Engine," SAE Paper 881633 (1988).

48. H. Becker et al., "Investigation of Flame Structure and Burning Behaviour in an IC Engine Simulator by 2D-LIF of OH Radicals," Appl. Phys. B 50, 473-478 (1990).

49. P. Andresen et al., "Fluorescence Imaging Inside an Internal Combustion Engine Using Tunable Excimer Lasers," Appl. Opt. 29, 2392-2404 (1990).

50. P. G. Felton, J. Mantzaras, M. E. A. Bardsley, and F. V. Bracco, "2-D Visualization of Liquid Fuel Injection in an Internal Combustion Engine," SAE Paper 872074 (1987).

51. L. A. Melton and J. F. Verdieck, "Vapor/Liquid Vizualization for Fuel Sprays," Combust. Sci. Tech. 42, 217-222 (1985).

52. M. E. A. Bardsley, P. G. Felton, and F. V. Bracco, "2-D Visualization of Liquid and Vapor Fuel in an I.C. Engine," SAE Paper 880521 (1988).

53. M. E. A. Bradsley, P. G. Felton, and F. V. Bracco, "2-D Visualization of a Hollow-Cone Spray in a Cup-in-Head, Ported, I.C. Engine," SAE Paper 890315 (1989).

54. M. G. Allen and R. K. Hanson, "Digital Imaging of Species Concentration Fields in Spray Flames," in Twenty-First International Symposium on Combustion (Combustion Institute, Pittsburgh, 1986), pp. 1755-1762.

55. M. G. Allen and R. K. Hanson, "Planar Laser-Induced-Fluorescence Monitoring of $\mathrm{OH}$ in a Spray Flame," Opt. Eng. 25, 13091311 (1986).

56. W. Hentschel, "Application of Lasers for in-Cylinder Studies and Flow Visualization" (in German), VDI Ber. 617, 347-376 (1986).

57. W. Hentschel, H. Hesse, and K. P. Schindler, "Experimental Investigation of Spray Formation and Combustion in a Real Diesel Engine," Autotech 89, Birmingham (1989), paper 399. 